\title{
Modeling and Optimization of Reactive Cotton Dyeing Using Response Surface Methodology Combined with Artificial Neural Network
}

\section{Jorge Marcos Rosa}

State University of Campinas: Universidade Estadual de Campinas

Flavio Guerhardt

Universidade Nove de Julho

Silvestre Eduardo Rocha Rocha Ribeiro Júnior

Universidade Nove de Julho

\section{Peterson Adriano Belan}

Universidade Nove de Julho

\section{Gustavo Araujo Lima}

Universidade Nove de Julho

José Carlos Curvelo Santana

Federal University of $A B C$

Fernando Tobal Berssaneti

University of Sao Paulo: Universidade de Sao Paulo

\section{Elias Basile Tambourgi}

State University of Campinas: Universidade Estadual de Campinas

\section{Rosangela Maria Vanale}

Universidade Nove de Julho

Sidnei Alves de Araújo ( $\nabla$ saraujo@uni9.pro.br)

Universidade Nove de Julho https://orcid.org/0000-0003-3970-5801

\section{Research Article}

Keywords: dyeing of cotton, reactive dyestuff, coloristic intensity, response surface methodology, artificial neural network

Posted Date: February 19th, 2021

DOI: https://doi.org/10.21203/rs.3.rs-206863/v1

License: (c) (1) This work is licensed under a Creative Commons Attribution 4.0 International License. Read Full License 


\section{Abstract}

This work explores the modeling and optimization of the conditions to obtain a set of blue pigments for dyeing reactive cotton, by means of an approach that combines the techniques response surface methodology (RSM) and artificial neural network (ANN). By means of RSM technique the interactions and the effects of the main process variables (factors) on the behavior of

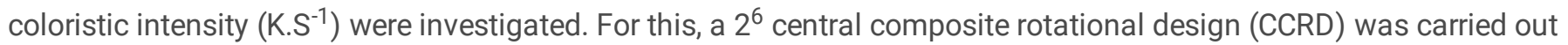
considering the factors temperature, $\mathrm{NaCl}, \mathrm{Na}_{2} \mathrm{CO}_{3}, \mathrm{NaOH}$, processing time and RB5 concentration. The results obtained show that all investigated factors have considerable effect on the behavior of $\mathrm{K}^{-1} \mathrm{~S}^{-1}$. The data produced in the dyeing experiments were used to build and train a Multilayer Perceptron ANN (MLP-ANN) to predict K.S $\mathrm{S}^{-1}$, being the input layer of the MLP-ANN designed according to the results achieved by the RSM. The non-linear behavior of dyeing with RB5 was successfully modeled by a three-layer MLP-ANN comprising 6 input neurons, 15 hidden neuros, and 1 output neuron to indicate the value of K.S ${ }^{-1}$. The results achieved in the performed simulations confirmed the ANN effectiveness to predict K.S ${ }^{-1}$ values in RB5 the dyeing process, with high coefficient of determination $\left(R^{2}=0.942\right)$. The developed approach allowed the composition of a table containing optimized conditions to obtain a set of colors of the blue palette using RB5 dye, varying from sky blue to oxford blue, which will facilitate the assembly of the dyes. Finally, the experiments conducted in this work allowed the development of a computational tool to support the dyeing process, saving chemical inputs and time in cotton dyeing with specific dyestuff.

\section{Introduction}

The Brazilian textile industry sector has a strong social impact. It employed nearly 1.6 million professionals in 2014 . This number corresponds to $16.9 \%$ of the total workers employed in industrial production. Moreover, this sector generates approximately US\$ 67 billion revenue in production, which corresponds to $5.5 \%$ of the entire industrial production revenue. In this sector, reactive dyestuff, which reacts with the fibre and water, is used widely for dyeing cellulosic fibres. Because of its reaction with water, this dyestuff is a major constituent of effluent; approximately $10-15 \%$ of the total dyestuff is disposed as a part of the effluent (Asgari et a., 2020; Lucato et al., 2012; Prado et al., 2013).

Therefore, it is important to optimize dyeing processes that use this reactive dyestuff in order to obtain the best coloristic intensity, minimise the salt discharge, and reduce the pollutants in the generated effluent. Reactive dyestuff causes undesirable levels of dissolved solids and oxygen demand in the effluent (do Nascimento et al., 2018; Rosa et al., 2020). This is because of the large quantities of inorganic salt and alkali used to ensure efficient utilisation and fixation of dyestuffs, which are largely non-biodegradable and toxic to aquatic life (Fernandes et al, 2020; Rosa et al., 2015). Moreover, many commercial dyestuffs are a cocktail of active dyestuff and various by-products that are recalcitrant to biological degradation and accumulate in the effluent after the dyeing process (Pauletto et al., 2020). Conventional wastewater treatment processes cannot degrade such compounds or detoxify the effluent. Therefore, alternative treatments should be developed (Padmanaban et al., 2018, Zin et al., 2020).

According to suppliers, C.I. Reactive Black 5 (RB5) dyestuff, which is the focus of this study, is the most marketed dyestuff in the world and consequently causes the most environmental pollution (Rosa et al., 2014; Rosa et al., 2020). It is a homobifunctional azo dye with vinyl sulfone as its reactive group, CAS Number 17095-24-8, and a molecular weight of $991.82 \mathrm{~g}$ $\mathrm{mol}^{-1}$. The appropriate use of this dye can minimise its presence in effluents and water bodies, thereby decreasing its impact on the environment.

Therefore, developing and applying techniques that optimize the fabric dyeing process are necessary to minimise the chemicals and water used, process costs, and environmental impacts, while maintaining the quality of textile products (Rosa et al., 2015; Rosa et al., 2020). The Kubelka-Munk model is one of the most popular method (Rosa et al., 2014) employed in the optimization of dyeing processes.

Based on the interaction of electromagnetic radiation with dyes (absorption or scattering), a computer color matching program determines the Kubelka-Munk absorption (K) and scattering coefficient (S) of pigments (Schabbach et al., 2018; Shen et al., 
2016). This model relates the reflectance to the light absorption and scattering of the added pigments. This model is commonly used to determine, predict, or formulate a specific color using calculation software in textile, paint, and ceramics industries (Schabbach et al., 2018).

By adjusting the $\mathrm{K} . \mathrm{S}^{-1}$ value, the best conditions for obtaining each color for dyeing can be established. However, there is no table with the formulation containing the ideal (optimal) conditions to obtain the colors of the blue palette using Reactive Blue 5 dye. The labels on products sold by the dye industry show a range of chemical substances to obtain these colors. Thus, the modeling and optimization of the process conditions to obtain each of the ten colors of the blue palette (varying from light blue to Oxford blue), which is the focus of this work, will facilitate the assembly of the dyes in optimal conditions.

\subsection{ANN in the textile industry}

Artificial neural networks (ANN) consist of an artificial intelligence (Al) technique inspired by the structure and functioning of the human brain (Haykin, 2007). The Multilayer Perceptron (MLP) is certainly the best-known model of ANN and most widely used in practical applications. It is a supervised learning model, trained by an algorithm called backpropagation, commonly used for solving nonlinear problems, that learns some function by training on a dataset. It is characterized by having, in addition to the input and output layers, one or more hidden layers that allow the network to map input patterns with similar structures, for different outputs (Haykin, 2007).

Although ANN is a technique created more than 50 years ago, its use has increased exponentially in the last two decades, in various fields of knowledge, especially for solving problems of pattern recognition and classification, regression, modeling and optimization. Such growth has been motivated mainly by the availability of computers with greater processing capacities and the increase in the number of software packages and libraries that facilitate the use of the technique (Bhapkar et al., 2019). It should be noted that specifically for optimization applications, other Al techniques such as genetic algorithms (Librantz et al., 2011; Fernandes et al. 2020; Tsao et al., 2020) and simulated annealing (Almeida et al., 2014; Tsao et al., 2020) are more appropriate and therefore they have been widely used in such applications.

In the field of engineering, for example, we can mention the application of ANN in various non-linear processes, such as: in civil engineering, where Müsevitoğlu et al. (2020) studied the behavior of chemical anchors embedded in concrete under the tensile effect; in hydrologic engineering, where Bhapkar et al. (2019) employed an ANN to estimate water level variations in dams based on rainfall data; in fluid dynamics, where Babikir et al. (2019) proposed the use of ANN to predict the noise of a submersible axial piston pump (APP) for different valve seat materials; in material engineering, where Maleki and Farrahi (2018) modeled and compared the effects of conventional shot peening and severe shot peening on the properties of AISI 1060 high carbon steel using an ANN; in chemical engineering, where Cao et al. (2016) developed an ANN to study the performance of the vacuum membrane distillation (VMD) desalination process under different operating parameters such as feed inlet temperature, vacuum pressure, feed flow rate, and feed salt concentration; in food engineering, where Santana et al. (2010) optimized the conditions for obtaining Barbados cherry wines, and Kalejahi and Asefi (2019) investigated the effects of infrared power on drying behavior of quince slice; and in environmental engineering, where Rosa et al. (2013) employed a Multilayer Perceptron artificial neural network (MLP-ANN) to simulate the variation in protein concentration according to the time and to determine the optimal conditions of the biodegradation process of wastewater from the meat industry or in protein biodegradation from meat effluent as demonstrated by Curvelo Santana et al. (2015).

Application of ANN in the textile industry has also been observed in recent decades, such as: in the prediction of the surface temperature of the fabrics (Bahadir et al., 2019); in heat and moisture propagation in light nonwoven fabrics (Rahnama et al., 2013); in the interaction between hetero cyclic dyestuffs and cellulose (Funar-Timofei et al., 2012); in removing dyes from textile effluents via adsorption onto chitosan-based hybrid hydrogels (Pauletto et al., 2020), by radiolytic degradation (Padmanaban et al, 2018), by biodegradation (Prado et al., 2013; Torbati et al., 2014) or $\mathrm{UV} / \mathrm{H}_{2} \mathrm{O}_{2}$, Fenton or photo-Fenton advanced oxidation processes (do Nascimento et al., 2017; Mohajerani et al., 2011; Rosa et al., 2015; Rosa et al., 2020; de Moraes et al., 2021). 
Recently, the textile industry has been studying the ANN combined with response surface methodology (RSM) in its processes (Vedaraman et al., 2017) and mainly in the treatment of textile effluent, such as: in reactive blue 21 dye removal by photoozonation process (Mehrizad and Gharbani, 2016), in the degradation of organic dyes by sonochemistry combined with $\mathrm{Au}, \mathrm{Ag}$ and Pd nanoparticle (Moghaddari et al., 2018), in sonophotocatalytic degradation of AB113 dye using ZnO/persulfate (Asgari et a., 2020) or in azo dye RB5 biodegradation using fungal enzymes (Fernandes et al., 2020). However, there are no studies using ANN and RSM techniques in predicting the color of a dye using the intensity of color.

It is known that textile companies prepare their dyeing using old formulas, without checking if they are using excessive chemicals, water, energy and cost. In Brazil, for example, much of the textile effluent with high chemical concentration is currently discarded without having undergone proper treatment and thus contaminate water bodies, such as rivers and lakes. So, it is very important to use methods that manage to minimize the consumption of inputs and the costs in the textile processes (Rosa et al., 2015).

The literature revision evidence the importance of modeling and optimizing dyeing processes using reactive dyestuffs to obtain better coloristic intensity, minimizing salt discharge and reducing pollutants in the effluent. Thus, this work focuses on modeling and optimization the conditions for obtaining a set of blue colors by means of an approach that combines RSM with MLP-ANN techniques. In other words, we investigated the interactions and the effects of the main process variables on the behavior of coloristic intensity $\left(K \cdot S^{-1}\right)$ by means RSM technique as a first step of the dyeing process optimization; we built and trained a Multilayer Perceptron ANN (MLP-ANN) from the data produced in the dyeing experiments for predicting K. $S^{-1}$ values; and finally, applying the developed approach, we composed a table containing the compositions to obtain colors varying from light blue to oxford blue of the blue palette using RB5 dye, which will facilitate the assembly of the dyes in optimal conditions.

\section{Experiment}

\subsection{Dyeing process design}

The experimental work was developed in a partner company of the Sorocaba technology park. All 78 samples were bleached and dyed (Mathis Alt-1) according to the process described by Rosa et al. (2015). The dyeing experiments were supported by a $2^{6}$ central composite rotational design (CCRD) and the studied factors were temperature, $\mathrm{T} ; \mathrm{NaCl}$ concentration, $\left[\mathrm{NaCl}_{3} ; \mathrm{Na}_{2} \mathrm{CO}_{3}\right.$ concentration, [ $\mathrm{Na}_{2} \mathrm{CO}_{3}$ ]; $\mathrm{NaOH}$ concentration, [NaOH]; processing time, Time and RB5 concentration, [RB5] (Almeida et al., 2012; Benvenga et al., 2016; Klepa et al., 2019). These factors went through variable coding as shown in Table 1. All factors were varied according to the dyeing formulations recommended by the manufacturer that reflect coloristic intensities varying from sky blue (K.S $\mathrm{S}^{-1} @ 6$ ) to Oxford blue (K.S $\left.{ }^{-1} @ 31\right)$. Some axial values were not obtained experimentally, as they were beyond the limit process conditions (Rosa et al., 2015; Rosa et al., 2020). The coloristic intensity is a response for a set of values of the six factors (process variables).

Table 1. Coded factors used in the design of experiment 


\begin{tabular}{|llllll|}
\hline Factors & \multicolumn{2}{c}{ Levels } & & & \\
& -2.83 & -1 & 0 & +1 & +2.83 \\
\hline Temperature, $\mathrm{T}\left({ }^{\circ} \mathrm{C}\right)$ & 22 & 40 & 50 & 60 & 78 \\
\hline $\mathrm{NaCl}$ concentration, $[\mathrm{NaCl}]\left(\mathrm{g} \cdot \mathrm{L}^{-1}\right)$ & - & 20 & 40 & 60 & 97 \\
$\mathrm{Na}_{2} \mathrm{CO}_{3}$ concentration, $\left[\mathrm{Na}_{2} \mathrm{CO}_{3}\right]\left(\mathrm{g} \cdot \mathrm{L}^{-1}\right)$ & 0.425 & 5.0 & 7.0 & 10 & 14.575 \\
$\mathrm{NaOH}$ concentration, $[\mathrm{NaOH}]\left(\mathrm{mL}^{\mathrm{L}} \mathrm{L}^{-1}\right)$ & - & 0.50 & 1.50 & 2.50 & 4.30 \\
\hline Processing time, Time, $(\mathrm{min})$ & - & 30 & 60 & 90 & 145 \\
\hline RB5 concentration, $[\mathrm{RB} 5]\left(\mathrm{g} . \mathrm{L}^{-1}\right)$ & - & 1.00 & 2.00 & 3.00 & 4.80 \\
\hline
\end{tabular}

A square model was obtained by the least squares method and its fit was made by the method of analysis of variance (ANOVA). The first optimization of the dying process was performed using the RSM and effect analysis. The model, ANOVA and response surfaces using CCRD (RSM-CCRD) were obtained using software Statistica $10 \circledast$ for Windows.

The response variable $\left(\mathrm{K} . \mathrm{S}^{-1}\right)$ of the experimental planning (Table 1) was fitted to a second order polynomial equation, aiming to correlate the response variable with the independent variables (factors). The RSM-CCRD model which considered the linear, hyperbolic, and square interaction effects of the process variables was used for the preliminary regression fits using the Equation 1 , in which $y$ is the response variable, $X_{\mathrm{i}}=$ term of independent factor, $b_{0}=$ intercept, $b_{l}=$ linear model coefficient, $b_{i i}=$ quadratic coefficient for the factor $i$, and $b_{i j}=$ linear model coefficient for the interaction between factors $i$ and $j$. (Almeida et al., 2012; Benvenga et al., 2016; Klepa et al., 2019).

$$
\mathrm{y}=\beta_{0}+\sum_{i=1}^{6} \beta_{i} X_{i}+\sum_{i=1}^{6} \beta_{i i} X_{i}^{2}+\sum_{i=1}^{5} \sum_{j=i+1}^{6} \beta_{i j} X_{j} X_{j}
$$

The K.S $\mathrm{S}^{-1}$ was determined using the Kubelka-Munk equation (Equation 2), in which $R$ means the reflectance of the samples (Rosa et al., 2014; Rosa et al., 2020).

$$
F_{k=m}=K / S=\frac{(1-R)^{2}}{2 R}
$$

The samples' reflectances were measured using visible spectrophotometry, under D65 illuminant at $10^{\circ}$ (Konica-Minolta CM 3600d) (Kazemi-Beydokhti et al., 2015).

Dyeing cost is given as the sum of the costs of inputs and utilities used in the process. Each input cost is given by multiplying the input price for its consumption by $\mathrm{m}^{3}$ of dyeing, as shown in Equation 3 (Klepa et al., 2019; Miranda et al., 2018). Table 2 shows the prices of inputs and utilities consumed in the dyeing process.

$$
\operatorname{Cost}\left(U S \$ / m^{3}\right)=\sum_{i=1}^{4} \text { Input }_{i} \text { Price }_{i}+\sum_{j=1}^{2} \text { Utility }_{j} \text {. } \text { Price }_{j}
$$

Table 2. Prices of inputs and utilities consumed in the dyeing process (in 2018) 


\begin{tabular}{|lll|}
\hline Input/Utility & Unity & Price (US\$) \\
\hline Reactive Black 5 (RB5) & $\mathrm{Kg}$ & 18.00 \\
$\mathrm{NaCl}$ & $\mathrm{Kg}$ & 1.20 \\
$\mathrm{Na} 2 \mathrm{CO} 3$ & $\mathrm{Kg}$ & 2.60 \\
$\mathrm{NaOH}\left(50^{\circ} \mathrm{Be}\right)$ & $\mathrm{L}$ & 1.80 \\
\hline Treated water & $\mathrm{m}^{3}$ & 11.05 \\
\hline Natural gas & $\mathrm{m}^{3}$ & 0.69 \\
\hline
\end{tabular}

\subsection{Artificial Neural Network}

An MLP-ANN developed in Python was employed to predict the coloristic intensity from a set of values of the process variables ( $\mathrm{T},[\mathrm{NaCl}],\left[\mathrm{Na}_{2} \mathrm{CO}_{3}\right],[\mathrm{NaOH}]$, Time and [RB5]).

As illustrated in Figure 1, the MLP-ANN, which acts as a regression model, consists of six input neurons and one output neuron to indicate the value of $\mathrm{K}_{\mathrm{S}} \mathrm{S}^{-1}$. Notice that the six process variables were considered as the input of MLP-ANN because the results obtained by RMS (described in section 3.1) show that all of them have considerable effect on the behavior of K.S ${ }^{-1}$.

\section{Figure 1. Base architecture of developed MLP-ANN}

In order to obtain an optimized structure, some networks with different numbers of neurons in the hidden layer (hidden layer size - hls) were studied and the performance of each designed MLP-ANN were evaluated by means of the determination coefficient $\left(R^{2}\right)$ and mean square error (MSE). In this study we considered hls $=\{5,10,15,20\}$.

The values adopted for main configuration parameters of each MLP-ANN architecture (activation function, learning rate and momentum) were obtained by means of a grid search method which aimed to perform an exhaustive search to find for the best configuration considering a set of predetermined values for each parameter. The activation function of a node defines the output of that node given a set of inputs; learning rate is a parameter that controls the changes in the ANN in response to the estimated error each time the ANN weights are updated; and the momentum is a parameter that helps accelerate gradients vectors in the right directions, leading to faster converging of backpropagation training algorithm (Haykin, 2007).

Before evaluating the four MLP-ANN architectures we randomly split data produced in the dyeing experiments (experimental data showed in Table 3 ) into training (66.66\%) and prediction (33.34\%) subsets. The prediction subset was employed to verify the MLP-ANN performance in producing K. $\mathrm{S}^{-1}$ values for samples not used in the training step. Then, the MLP-ANN was executed ten times considering each architecture. Each training was interrupted (stop criteria) when the maximum epochs $(10,000)$ was reached or when the loss did not improve after at least 500 consecutive epochs. The results produced by the four evaluated MLP-ANN architectures are presented in Table 4.

\section{Results}

\subsection{Response surfaces}

Table 3 shows the K.S ${ }^{-1}$ values obtained after execution of each assay according to experimental planning adopted in this work.

Table 3. Planning matrix used in the dyeing experiments 


\begin{tabular}{|c|c|c|c|c|c|c|c|c|c|c|c|c|c|c|c|}
\hline Assay & $X_{1}$ & $x_{2}$ & $x_{3}$ & $x_{4}$ & $X_{5}$ & $x_{6}$ & $\mathrm{y}\left(\mathrm{K} \cdot \mathrm{S}^{-1}\right)$ & Assay & $x_{1}$ & $x_{2}$ & $x_{3}$ & $X_{4}$ & $X_{5}$ & $x_{6}$ & $y\left(K . S^{-1}\right)$ \\
\hline 1 & -1 & -1 & -1 & -1 & -1 & -1 & 5.2139 & 40 & +1 & +1 & +1 & -1 & -1 & +1 & 31.5600 \\
\hline 2 & +1 & -1 & -1 & -1 & -1 & -1 & 11.7160 & 41 & -1 & -1 & -1 & +1 & -1 & +1 & 10.6490 \\
\hline 3 & -1 & +1 & -1 & -1 & -1 & -1 & 6.1281 & 42 & +1 & -1 & -1 & +1 & -1 & +1 & 18.4890 \\
\hline 4 & +1 & +1 & -1 & -1 & -1 & -1 & 14.9940 & 43 & -1 & +1 & -1 & +1 & -1 & +1 & 11.8140 \\
\hline 5 & -1 & -1 & +1 & -1 & -1 & -1 & 6.5652 & 44 & +1 & +1 & -1 & +1 & -1 & +1 & 26.1420 \\
\hline 6 & +1 & -1 & +1 & -1 & -1 & -1 & 11.8040 & 45 & -1 & -1 & +1 & +1 & -1 & +1 & 14.2200 \\
\hline 7 & -1 & +1 & +1 & -1 & -1 & -1 & 8.8501 & 46 & +1 & -1 & +1 & +1 & -1 & +1 & 20.2410 \\
\hline 8 & +1 & +1 & +1 & -1 & -1 & -1 & 14.5520 & 47 & -1 & +1 & +1 & +1 & -1 & +1 & 16.4460 \\
\hline 9 & -1 & -1 & -1 & +1 & -1 & -1 & 4.8820 & 48 & +1 & +1 & +1 & +1 & -1 & +1 & 27.7660 \\
\hline 10 & +1 & -1 & -1 & +1 & -1 & -1 & 6.5314 & 49 & -1 & -1 & -1 & -1 & +1 & +1 & 24.9280 \\
\hline 11 & -1 & +1 & -1 & +1 & -1 & -1 & 5.6355 & 50 & +1 & -1 & -1 & -1 & +1 & +1 & 23.6780 \\
\hline 12 & +1 & +1 & -1 & +1 & -1 & -1 & 11.4850 & 51 & -1 & +1 & -1 & -1 & +1 & +1 & 28.9790 \\
\hline 13 & -1 & -1 & +1 & +1 & -1 & -1 & 5.9026 & 52 & +1 & +1 & -1 & -1 & +1 & +1 & 28.7100 \\
\hline 14 & +1 & -1 & +1 & +1 & -1 & -1 & 9.4584 & 53 & -1 & -1 & +1 & -1 & +1 & +1 & 24.1220 \\
\hline 15 & -1 & +1 & +1 & +1 & -1 & -1 & 6.5032 & 54 & +1 & -1 & +1 & -1 & +1 & +1 & 25.4530 \\
\hline 16 & +1 & +1 & +1 & +1 & -1 & -1 & 13.2310 & 55 & -1 & +1 & +1 & -1 & +1 & +1 & 30.0260 \\
\hline 17 & -1 & -1 & -1 & -1 & +1 & -1 & 11.7890 & 56 & +1 & +1 & +1 & -1 & +1 & +1 & 30.6300 \\
\hline 18 & +1 & -1 & -1 & -1 & +1 & -1 & 9.5109 & 57 & -1 & -1 & -1 & +1 & +1 & +1 & 21.0950 \\
\hline 19 & -1 & +1 & -1 & -1 & +1 & -1 & 13.4900 & 58 & +1 & -1 & -1 & +1 & +1 & +1 & 16.3420 \\
\hline 20 & +1 & +1 & -1 & -1 & +1 & -1 & 12.1590 & 59 & -1 & +1 & -1 & +1 & +1 & +1 & 25.1180 \\
\hline 21 & -1 & -1 & +1 & -1 & +1 & -1 & 13.0700 & 60 & +1 & +1 & -1 & +1 & +1 & +1 & 23.1640 \\
\hline 22 & +1 & -1 & +1 & -1 & +1 & -1 & 11.7090 & 61 & -1 & -1 & +1 & +1 & +1 & +1 & 20.7260 \\
\hline 23 & -1 & +1 & +1 & -1 & +1 & -1 & 13.3190 & 62 & +1 & -1 & +1 & +1 & +1 & +1 & 16.8880 \\
\hline 24 & +1 & +1 & +1 & -1 & +1 & -1 & 13.3140 & 63 & -1 & +1 & +1 & +1 & +1 & +1 & 26.2660 \\
\hline 25 & -1 & -1 & -1 & +1 & +1 & -1 & 9.5905 & 64 & +1 & +1 & +1 & +1 & +1 & +1 & 23.6330 \\
\hline 26 & +1 & -1 & -1 & +1 & +1 & -1 & 7.2762 & 65 & 0 & 0 & 0 & 0 & 0 & 0 & 22.7610 \\
\hline 27 & -1 & +1 & -1 & +1 & +1 & -1 & 12.2360 & 66 & 0 & 0 & 0 & 0 & 0 & 0 & 22.1470 \\
\hline 28 & +1 & +1 & -1 & +1 & +1 & -1 & 9.6044 & 67 & 0 & 0 & 0 & 0 & 0 & 0 & 22.4420 \\
\hline 29 & -1 & -1 & +1 & +1 & +1 & -1 & 8.9137 & 68 & 0 & 0 & 0 & 0 & 0 & 0 & 21.8600 \\
\hline 30 & +1 & -1 & +1 & +1 & +1 & -1 & 7.4581 & 69 & 0 & 0 & 0 & 0 & 0 & 0 & 22.5150 \\
\hline 31 & -1 & +1 & +1 & +1 & +1 & -1 & 12.3940 & 70 & 0 & 0 & 0 & 0 & 0 & 0 & 22.3450 \\
\hline 32 & +1 & +1 & +1 & +1 & +1 & -1 & 10.5030 & 71 & -2.83 & 0 & 0 & 0 & 0 & 0 & 23.282 \\
\hline 33 & -1 & -1 & -1 & -1 & -1 & +1 & 9.2214 & 72 & 2.83 & 0 & 0 & 0 & 0 & 0 & 14.214 \\
\hline 34 & +1 & -1 & -1 & -1 & -1 & +1 & 25.8550 & 73 & 0 & 2.83 & 0 & 0 & 0 & 0 & 23.049 \\
\hline
\end{tabular}




\begin{tabular}{|c|c|c|c|c|c|c|c|c|c|c|c|c|c|c|c|}
\hline 35 & -1 & +1 & -1 & -1 & -1 & +1 & 10.5360 & 74 & 0 & 0 & -2.83 & 0 & 0 & 0 & 20.288 \\
\hline 36 & +1 & +1 & -1 & -1 & -1 & +1 & 31.1870 & 75 & 0 & 0 & 2.83 & 0 & 0 & 0 & 20.751 \\
\hline 37 & -1 & -1 & +1 & -1 & -1 & +1 & 13.6280 & 76 & 0 & 0 & 0 & 2.83 & 0 & 0 & 15.249 \\
\hline 38 & +1 & -1 & +1 & -1 & -1 & +1 & 22.7150 & 77 & 0 & 0 & 0 & 0 & 2.8 & 0 & 20.020 \\
\hline 39 & -1 & +1 & +1 & -1 & -1 & +1 & 17.2130 & 78 & 0 & 0 & 0 & 0 & 0 & 2.83 & 31.902 \\
\hline
\end{tabular}

After applying the least squares method on the experimental data set, several models were obtained and the one that fitted better is showed in Equation 4. As noted, the model has 47 parameters which show the dependence of the response with the six factors on linear, square and hyperbolic forms. It fitted the experimental with a correlation coefficient of 0.972 that corresponds to an $\mathrm{R}^{2}$ value of 0.945 .

$$
\begin{aligned}
& \mathrm{y}=21.2098+1.1576 * x_{1}+1.9929 * x_{2}+0.5279 * x_{3}-1.3504 * x_{4}+1.9462 * \\
& x_{5}+6.0507 * x_{6}-0.5191 * x_{1}^{2}-0.8979 * x_{2}^{2}-0.2979 * x_{3}^{2}-0.6904 * x_{4}^{2}- \\
& 1.2596 * x_{5}^{2}-1.2264 * x_{6}^{2}+0.5792 * x_{1} * x_{2}-0.1998 * x_{1} * x_{3}-0.7289 * x_{1} * \\
& x_{4}-2.6617 * x_{1} * x_{5}+0.8850 * x_{1} * x_{6}+0.1362 * x_{2} * x_{3}+0.1345 * x_{2} * x_{4}+ \\
& 0.6864 * x_{2} * x_{6}-0.3035 * x_{3} * x_{5}+0.1613 * x_{3} * x_{6}-0.4896 * x_{4} * x_{5}- \\
& 0.3572 * x_{4} * x_{6}+0.7686 * x_{5} * x_{6}+0.1211 * x_{1} * x_{2} * x_{4}-0.3977 * x_{1} * x_{2} * \\
& x_{5}+0.2121 * x_{1} * x_{2} * x_{6}+0.1933 * x_{1} * x_{3} * x_{4}+0.4352 * x_{1} * x_{3} * x_{5}-0.2686 * \\
& x_{1} * x_{3} * x_{6}+0.2004 * x_{1} * x_{4} * x_{5}-0.3588 * x_{1} * x_{4} * x_{6}-0.8692 * x_{1} * x_{5} * x_{6}+ \\
& 0.1811 * x_{2} * x_{3} * x_{6}+0.1237 * x_{2} * x_{4} * x_{5}+0.1133 * x_{2} * x_{5} * x_{6}-0.1898 * x_{3} * \\
& x_{4} * x_{5}-0.3587 * x_{4} * x_{5} * x_{6}-0.1275 * x_{1} * x_{2} * x_{5} * x_{6}-0.3140 * x_{1} * x_{3} * \mathrm{x} 4 . \\
& x_{5}+0.2638 * x_{1} * x_{3} * x_{5} * x_{6}+0.1634 * x_{2} * x_{3} * x_{4} * x_{5}-0.1138 * x_{2} * x_{3} * x_{4} * \\
& x_{6}+0.1381 * x_{1} * x_{2} * x_{4} * x_{5} * x_{6}-0.1027 * x_{1} * x_{2} * x_{3} * x_{5} * x_{6}
\end{aligned}
$$

The Figure 2 shows the effect analysis of factors on coloristic intensity. It was observed that $T$, [ $\mathrm{NaCl}],\left[\mathrm{Na}_{2} \mathrm{CO}_{3}\right]$, Time and [RB5] increase proportionally the value of $\mathrm{K} . \mathrm{S}^{-1}$. However, the interaction between $[\mathrm{NaOH}]$ and $\mathrm{K} . \mathrm{S}^{-1}$ was inversely proportional. [RB5] shows the greatest influence on $\mathrm{K} \mathrm{S}^{-1}$ values among the factors and experimental conditions studied, while $\mathrm{NaOH}$ has a low influence on $\mathrm{K}^{-\mathrm{S}^{-1}}$ values.

\subsection{Developed MLP-ANN}

The results obtained by the four MLP-ANN architectures in predicting coloristic intensity from the data are presented in Table 4 . The results of each architecture, differentiated by the number of neurons in the hidden layer (hls), are presented in terms of $\mathrm{R}^{2}$ values obtained in the training step (Train $R^{2}$ ), and $R^{2}$ and MSE values obtained in the prediction step. The last two rows of Table 4 present the average and standard deviation of $R^{2}$ and MSE values.

As can be seen, considering the average values and standard deviations of $\mathrm{R}^{2}$ and MSE, the best outcome was obtained using the MLP-ANN with 15 neurons in the hidden layer. The MLP-ANN employing 6,15 and 1 neurons reached average $R^{2}$ values 
(training and prediction) of 0.980 and 0.875 and an average MSE of 7.392 in the predictions. The low standard deviation values of $R^{2}$ and MSE (0.043 and 2.534) indicate the stability of MLP-ANN model in making predictions.

Table 4. Results obtained by the developed MLP-ANN

\begin{tabular}{|c|c|c|c|c|c|c|c|c|c|c|c|c|}
\hline \multirow[t]{4}{*}{ Run } & \multicolumn{12}{|c|}{ Hidden layer size (hls) } \\
\hline & \multicolumn{3}{|l|}{ hls $=5$} & \multicolumn{3}{|l|}{ hls $=10$} & \multicolumn{3}{|l|}{ hls $=15$} & \multicolumn{3}{|l|}{ hls $=20$} \\
\hline & \multirow{2}{*}{$\begin{array}{l}\text { Train. } \\
\mathrm{R}^{2}\end{array}$} & \multicolumn{2}{|c|}{ Prediction } & \multirow{2}{*}{$\begin{array}{l}\text { Train. } \\
\mathrm{R}^{2}\end{array}$} & \multicolumn{2}{|c|}{ Prediction } & \multirow{2}{*}{$\begin{array}{l}\text { Train. } \\
\mathrm{R}^{2}\end{array}$} & \multicolumn{2}{|c|}{ Prediction } & \multirow{2}{*}{$\begin{array}{l}\text { Train. } \\
\mathrm{R}^{2}\end{array}$} & \multicolumn{2}{|c|}{ Prediction } \\
\hline & & $\mathrm{R}^{2}$ & MSE & & $\mathrm{R}^{2}$ & MSE & & $\mathrm{R}^{2}$ & MSE & & $\mathrm{R}^{2}$ & MSE \\
\hline 1 & 0.915 & 0.846 & 9.060 & 0.972 & 0.706 & 17.356 & 0.976 & 0.884 & 6.849 & 0.997 & 0.888 & 6.614 \\
\hline 2 & 0.958 & 0.874 & 7.436 & 0.993 & 0.826 & 10.247 & 0.992 & 0.883 & 6.874 & 0.996 & 0.859 & 8.304 \\
\hline 3 & 0.855 & 0.879 & 7.151 & 0.986 & 0.846 & 9.088 & 0.993 & 0.839 & 9.485 & 0.997 & 0.914 & 5.094 \\
\hline 4 & 0.901 & 0.710 & 17.085 & 0.920 & 0.754 & 14.519 & 0.994 & 0.887 & 6.658 & 0.996 & 0.796 & 12.039 \\
\hline 5 & 0.901 & 0.734 & 15.661 & 0.952 & 0.873 & 7.475 & 0.938 & 0.890 & 6.508 & 0.942 & 0.830 & 10.003 \\
\hline 6 & 0.448 & 0.374 & 36.901 & 0.992 & 0.871 & 7.607 & 0.995 & 0.900 & 5.878 & 0.996 & 0.775 & 13.270 \\
\hline 7 & 0.849 & 0.833 & 9.829 & 0.990 & 0.889 & 6.538 & 0.995 & 0.868 & 7.776 & 0.995 & 0.756 & 14.388 \\
\hline 8 & 0.908 & 0.751 & 14.675 & 0.978 & 0.798 & 11.886 & 0.988 & 0.885 & 6.778 & 0.997 & 0.906 & 5.521 \\
\hline 9 & 0.656 & 0.700 & 17.661 & 0.932 & 0.864 & 8.004 & 0.933 & 0.768 & 13.675 & 0.997 & 0.934 & 3.899 \\
\hline 10 & 0.880 & 0.706 & 17.313 & 0.984 & 0.933 & 3.934 & 0.991 & 0.942 & 3.437 & 0.995 & 0.871 & 7.623 \\
\hline Average & 0.827 & 0.741 & 15.277 & 0.970 & 0.836 & 9.665 & 0.980 & 0.875 & 7.392 & 0.991 & 0.853 & 8.676 \\
\hline $\begin{array}{l}\text { Standard } \\
\text { deviation }\end{array}$ & 0.148 & 0.140 & 8.228 & 0.025 & 0.064 & 3.778 & 0.023 & 0.043 & 2.534 & 0.016 & 0.058 & 3.434 \\
\hline
\end{tabular}

The results of predictions made for the subset of data not used in the training step (prediction subset) by MLP-ANN that produced the best result $\left(R^{2}=0.942\right.$ and MSE $\left.=3.437\right)$ are illustrated in the graph in Figure 3 . This model together with its configuration parameters (activation function $=$ 'logistic', learning rate $=0.001$, and momentum $=0.9$ ) was saved and incorporated in the computational tool developed for supporting the dyeing process.

The results showed in Table 4 and Figure 3 confirm the significance of the MLP-ANN model for predicting K.S ${ }^{-1}$ values in the studied conditions. It is valid to emphasize that applying the RSM-CCRD model to make predictions in the same subset of samples used to evaluate the performance of MLP-ANN, the obtained R2 value was 0.938 .

The good results achieved by MLP-ANN enabled its use for the composition of the Table 5 which contemplates optimized conditions to obtain a set of colors of the blue palette using RB5 dye. For this purpose, groups of combinations of process

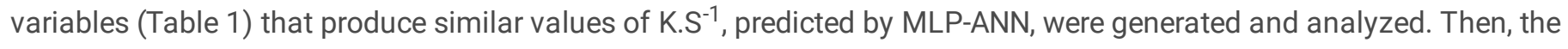
combination of each group that leads to the lowest cost, calculated form the Equation 3 and the data presented in Table 2, was selected to compose the Table 5. Obviously, the use of MLP-ANN combined with metaheuristic techniques such as genetic algorithms or particle swarm would be a more elegant way to produce this table. Nevertheless, the metaheuristics techniques were not the focus of this work and will be explored in our future work.

Table 5. Optimized conditions to obtain a set of colors varying from sky blue to oxford blue 


\begin{tabular}{|c|c|c|c|c|c|c|c|}
\hline \multicolumn{6}{|c|}{ Condition } & \multirow[t]{2}{*}{ K.S $\mathrm{S}^{-1}$ predicted by MLP-ANN } & \multirow{2}{*}{$\begin{array}{l}\text { Custo } \\
\text { US\$/ } \mathrm{m}^{3}\end{array}$} \\
\hline $\mathrm{T}$ & {$[\mathrm{NaCl}]$} & [Na2CO3] & {$[\mathrm{NaOH}]$} & Time & [RB5] & & \\
\hline 22 & 20 & 0,425 & 4,3 & 60 & 1 & 6,174 & 223,586 \\
\hline 22 & 20 & 5 & 2,5 & 60 & 1 & 8,057 & 232,241 \\
\hline 22 & 20 & 5 & 2,5 & 90 & 1 & 10,811 & 232,241 \\
\hline 40 & 20 & 7 & 0,5 & 90 & 1 & 14,142 & 233,854 \\
\hline 50 & 60 & 5 & 0,5 & 90 & 1 & 17,083 & 276,458 \\
\hline 50 & 20 & 0,425 & 1,5 & 90 & 2 & 20,694 & 398,419 \\
\hline 60 & 20 & 7 & 0,5 & 60 & 2 & 23,550 & 413,696 \\
\hline 78 & 60 & 10 & 0,5 & 60 & 2 & 26,089 & 469,278 \\
\hline 78 & 40 & 5 & 0,5 & 60 & 3 & 29,445 & 612,245 \\
\hline 78 & 40 & 7 & 0,5 & 60 & 3 & 31,406 & 617,436 \\
\hline
\end{tabular}

The results reported in this section confirms that the developed MLP-ANN can be used to obtain the best chemical compositions for colors of mentioned spectrum using RB5 dye, providing a reduction in the consumption of chemicals, water and the costs involved in the acquisition of these inputs. This also allows to reduce the environmental impacts of the dumping of chemical reagents and dyes.

Brazilian textile companies use archaic methods to formulate dyeing and the consumption of inputs and energy is high, consequently the costs of production and environmental fines are high (Rosa et al., 2020; Rosa et al., 2015; Miranda et al., 2018; Klepa et al., 2019). The costs observed in these companies to prepare their dyeing usually range from US\$ 350 to US\$ 1050, which corroborates the importance of the data presented Table 5. Thus, after implementing the MLP-ANN system in the processing control and based on environmental cost accounting, some advantages can be obtained, such as the following:

- Using achieved conditions, chemicals, water and energy consumption can be minimized;

- Expenses associated with the chemicals, water and energy cost for dyeing process can decrease from 8 to $20 \%$ using the optimized conditions presented in Table 5;

- Wastewater left from the dyeing process with a minimum amount of chemical waste;

- Decreasing expenses associated with the chemicals and energy cost used for effluent treatment. This will reduce expenses with the payment of environmental fines;

- Since the energy is generated by natural gas, there will be a reduction in energy consumption. It reduces $\mathrm{CO}_{2}$ emissions and thus can also provide carbon credits. Then, it is possible to make a profit from the sale of carbon credits on the stock exchange;

- Criticism associated with the environmental pollution caused by the company, in different types of news and social media would be avoided;

- Finally, by mitigating these environmental effects, the image of textile company could be improved, such as demonstrated in Rosa et al. (2020), Rosa et al. (2015), Miranda et al. (2018) and Klepa et al. (2019).

\section{Conclusion}

In this work simulations were performed to estimate RB5 dyeing under different conditions. The results produced by RSM demonstrated that all variables have considerable effect on the behavior of $\mathrm{K}_{\mathrm{S}} \mathrm{S}^{-1}$ and, for that reason, all of them were considered as input to the developed MLP-ANN. 
The non-linear behavior of dyeing with RB5 was successfully modeled by an MLP-ANN with three layers, being 6 input neurons, 15 hidden neurons and 1 output neuron to indicate the value of K.S ${ }^{-1}$. The values of $R^{2}$ and MSE (0.942 and 3.437) confirm the significance of the MLP-ANN in predicting $\mathrm{K} . \mathrm{S}^{-1}$ values in RB5 dyeing processes.

The approach developed in this work provided the composition of a table containing the compositions to obtain colors varying from light blue to oxford blue of the blue palette using RB5 dye, which will facilitate the assembly of the dyes in optimal conditions.

The experiments conducted in this work allowed the development of a computational tool to support the dyeing process, aiming to save chemical inputs and time in cotton dyeing with specific dyestuff.

Further studies are required using other dyestuffs, not only for dyeing cotton but also other fibres. Moreover, we intend to conduct a more complete study in the context of optimization, using metaheuristics such as Genetic Algorithm and Particle Swarm, aiming to maximize a wide range of coloristic intensities with the lowest possible costs, expanding the benefits already achieved in this work.

\section{Declarations}

\section{Acknowledgements}

We would like to thank the School of Technology SENAI Antoine Skaf, Parque Tecnológico de Sorocaba and Fundação Carlos Alberto Vanzolini for their support, and Golden Technology, supplier of chemicals used in this research. In addition, S. A. Araújo and J. C. C. Santana would like to thank the CNPq-Brazilian National Research Council for their research scholarship (Proc. 313765/2019-7 and 305987/2018-6).

\section{Funding}

This research was partially fund by CNPq-Brazilian National Research Council (research scholarship granted to the authors S. A. Araújo and J. C. C. Santana).

\section{Conflicts of interest/Competing interests}

No potential competing interest was reported by the authors.

\section{Availability of data and material}

The data produced in this research can be made available upon request.

\section{Code availability}

The codes implemented in Python in this research can be made available upon request.

\section{References}

Almeida, P.F., Araújo, M.G.O., Santana, J.C.C. (2012). Collagen extraction from chicken feet for jelly production. Acta Scientiarum - Technology, 34(3): 345-351. DOI: 10.4025/actascitechnol.v34i3.10602

Almeida, S. D. S., Alves, W. A. L., Araújo, S. A. D., Santana, J. C. C., Narain, N., Souza, R. R. D. (2014). Use of simulated annealing in standardization and optimization of the acerola wine production. Food Science and Technology, 34(2): 292-297. DOI: https://doi.org/10.1590/fst.2014.0037

Asgari, G., Shabanloo, A., Salari, M., \& Eslami, F. (2020). Sonophotocatalytic treatment of AB113 dye and real textile wastewater using $\mathrm{ZnO}$ /persulfate: Modeling by response surface methodology and artificial neural network. Environmental Research, 184: 
109367. DOI: https://doi.org/10.1016/j.envres.2020.109367

Babikir, H. A., Abd Elaziz, M., Elsheikh, A. H., Showaib, E. A., Elhadary, M., Wu, D., Liu, Y. (2019). Noise prediction of axial piston pump based on different valve materials using a modified artificial neural network model. Alexandria Engineering Journal, 58(3): 1077-1087. DOI: https://doi.org/10.1016/j.aej.2019.09.010

Bahadir, S. K., Sahin, U. K., \& Kiraz, A. (2019). Modeling of surface temperature distributions on powered e-textile structures using an artificial neural network. Textile Research Journal, 89(3): 311-321. DOI: https://doi.org/10.1177/0040517517743689

Benvenga, M. A. C., Librantz, A.F. H., Curvelo Santana, J. C. C., Tambourgi, E.B. (2016). Genetic algorithm applied to study of the economic viability of alcohol production from Cassava root from 2002 to 2013. Journal of Cleaner Production, 113: $483-494$. DOI: 0.1016/j.jclepro.2015.11.051

Bhapkar, A., Bante, S., Deshmukh, S., \& Shekokar, M. R. (2019). Estimation of Water Level Variations in Dams based on Rainfall Data using ANN. International Research Journal of Engineering and Technology (IRJET), 6(4): 3227-3232.

Cao, W., Liu, Q., Wang, Y., Mujtaba, I. M. (2016). Modeling and simulation of VMD desalination process by ANN. Computers \& Chemical Engineering, 84: 96-103. DOI: https://doi.org/10.1016/j.compchemeng.2015.08.019

Curvelo Santana, J. C, de Araújo, S. A, M. Biazus, J. P., de Souza, R. R. (2015). Simulation of biodegradation process of wastewater from meat industry by means of a multilayer perceptron artificial neural network. Ingeniare. Revista Chilena de Ingeniería, 23(2): 269-275. DOI: 10.4067/s0718-33052015000200011

de Moraes, N. F., Santana, R. M., Gomes, R. K., Júnior, S. G. S., de Lucena, A. L., Zaidan, L. E., \& Napoleão, D. C. (2021). Performance verification of different advanced oxidation processes in the degradation of the dye acid violet 17: reaction kinetics, toxicity and degradation prediction by artificial neural networks. Chemical Papers, 75: 539-552. DOI:

https://doi.org/10.1007/s11696-020-01325-9

do Nascimento, G. E., Napoleão, D. C., da Rocha Santana, R. M., Charamba, L. V. C., de Oliveira, J. G. C., de Moura, M. C., ... \& Duarte, M. M. M. B. (2018). Degradation of textile dyes Remazol Yellow Gold and reactive Turquoise: optimization, toxicity and modeling by artificial neural networks. Water Science and Technology, 2017(3): 812-823. DOI:

https://doi.org/10.2166/wst.2018.251

Fernandes, C. D., Nascimento, V. R. S., Meneses, D. B., Vilar, D. S., Torres, N. H., Leite, M. S., ... \& Ferreira, L. F. R. (2020). Fungal biosynthesis of lignin-modifying enzymes from pulp wash and Luffa cylindrica for azo dye RB5 biodecolorization using modeling by response surface methodology and artificial neural network. Journal of Hazardous Materials, 123094. DOI: https://doi.org/10.1016/j.jhazmat.2020.123094

Funar-Timofei, S., Fabian, W. M. F., Kurunczi, L., Goodarzi, M., Ali, S. T., Heyden, Y. V. (2012). Modelling heterocyclic azo dye affinities for cellulose fibres by computational approaches. Dyes Pigments, 94(2): 278-289. DOI:

https://doi.org/10.1016/j.dyepig.2012.01.015

Haykin, S. (2007). Neural networks: a comprehensive foundation, 3. ed. Prentice-Hall, Inc. Upper Saddle River, NJ, USA. 906p.

Kalejahi, A. K. and Asefi, N. (2019). Influence of vacuum impregnation pretreatment combined with IR drying on quince quality with shrinkage modeling by ANN. Chemical Engineering Communications, 206 (12), 1661-1675. DOI:

https://doi.org/10.1080/00986445.2019.1570161

Kazemi-Beydokhti, A., Azizi Namaghi, H., Haj Asgarkhani, M. A., Zeinali Heris, S., (2015). Prediction of stability and thermal conductivity of $\mathrm{SnO}_{2}$ nanofluid via statistical method and an artificial neural network. Brazilian Journal of Chemical Engineering, 32(4): 903-917. DOI: https://doi.org/10.1590/0104-6632.20150324s00003518

Page $12 / 16$ 
Klepa, R. B., Medeiros, M. F., Franco, M. A. C., Tamberg, E. T., Farias, T. M. B., Paschoalin Filho, J. A., Berssaneti, F. T., Santana, J. C. C. (2019). Reuse of construction waste to produce thermoluminescent sensor for use in highway traffic control. Journal of Cleaner Production, 209: 250-258. DOI: https://doi.org/10.1016/j.jclepro.2018.10.225

Librantz, A. F. H., Coppini, N. L., Baptista, E. A., Alves de Araújo, S., Castello Rosa, A. D. F. (2011). Genetic algorithm applied to investigate cutting process parameters influence on workpiece price formation. Materials and Manufacturing Processes, 26(3): 550-557. DOI: https://doi.org/10.1080/10426914.2010.512817

Lucato, W.C., Vieira Jr., M., Vanalle, R.M., Salles, J.A.A. (2012). Model to measure the degree of competitiveness for auto parts manufacturing companies. International Journal of Production Research, 50(19): 5508-5522 DOI:

https://doi.org/10.1080/00207543.2011.643252

Maleki, E. and Farrahi, G. H. (2018). Modelling of conventional and severe shot peening influence on properties of high carbon steel via artificial neural network. International Journal of Engineering, 31(2): 382-393.

Mehrizad, A. and Gharbani, P. (2016). Application of central composite design and artificial neural network in modeling of reactive blue 21 dye removal by photo-ozonation process. Water Science and Technology, 74(1): 184-193. DOI:

https://doi.org/10.2166/wst.2016.199

Miranda, A.C., da Silva Filho, S.C., Tambourgi, E.B., Vanalle, R.M., Guerhardt, F. (2018). Analysis of the costs and logistics of biodiesel production from used cooking oil in the metropolitan region of Campinas (Brazil). Renewable and Sustainable Energy Reviews, 88: 373-379. DOI: https://doi.org/10.1016/j.rser.2018.02.028

Moghaddari, M., Yousefi, F., Ghaedi, M., \& Dashtian, K. (2018). A simple approach for the sonochemical loading of Au, Ag and Pd nanoparticle on functionalized MWCNT and subsequent dispersion studies for removal of organic dyes: Artificial neural network and response surface methodology studies. Ultrasonics Sonochemistry, 42: 422-433. DOI: https://doi.org/10.1016/j.ultsonch.2017.12.003

Mohajerani, M., Mehrvar, M., Ein-Mozaffari, F. (2011). Nonlinear Modeling for the Degradation of Aqueous Azo Dyes by Combined Advanced Oxidation Processes Using Artificial Neural Networks. Chemical Product and Process Modeling, 6(1): 1934-2659. DOI: https://doi.org/10.2202/1934-2659.1562

Müsevitoğlu, A., Arslan, M. H., Aksoylu, C., \& Özkiş, A. (2020). Experimental and analytical investigation of chemical anchors's behavior under axial tensile. Measurement, 158: 107689. DOI: https://doi.org/10.1016/j.measurement.2020.107689

Padmanaban, V., Selvaraju, N., Vasudevan, V., \& Achary, A. (2018). Radiolytic degradation of reactive textile dyes by ionizing high energy ( $\mathrm{Y}$-Co60) radiation: artificial neural network modelling. Desalination and Water Treatment, 131: 343-350. DOI: doi:10.5004/dwt.2018.23039

Pauletto, P. S., Gonçalves, J. O., Pinto, L. A. A., Dotto, G. L., \& Salau, N. P. G. (2020). Single and competitive dye adsorption onto chitosan-based hybrid hydrogels using artificial neural network modeling. Journal of Colloid and Interface Science, 560: 722729. DOI: https://doi.org/10.1016/j.jcis.2019.10.106

Prado, K. R. M., Rosa, J. M., Santana, J. C. C., Tambourgi, Elias B., Alves, W. A. L., Pereira, F. H. (2013). A bootstrapped neural network model applied to prediction of the biodegradation rate of reactive Black 5 dye. Acta Scientiarum. Technology (Online), 35: 565-572. DOI: 10.4025/actascitechnol.v35i3.16210.

Rahnama, M., Semnani, D., Zarrebini, M. (2013). Measurement of the Moisture and Heat Transfer Rate in Light-weight Nonwoven Fabrics Using an Intelligent Model. Fibres \& Textiles in Eastern Europe, 6(102): 89-94.

Rosa, J. M., Prado, K. R. M., Alves, W. A. L., Pereira, F. H., Santana, J. C. C., Tambourgi, E. (2013). Applying of a neural network in effluent treatment simulation as an environmental solution for textile industry. Chemical Engineering Transactions, 32: 73-78. DOI: 10.3303/CET1332013

Page $13 / 16$ 
Rosa, J. M., Fileti, A. M. F., Tambourgi, E. B., Santana, J. C. C. (2015). Dyeing of cotton with reactive dyestuffs: the continuous reuse of textile wastewater effluent treated by Ultraviolet/Hydrogen peroxide homogeneous photocatalysis. Journal of Cleaner Production, 90: 60-65. DOI: https://doi.org/10.1016/j.jclepro.2014.11.043

Rosa, J. M., Tambourgi, E. B., Santana, J. C. C., Araujo, M. C., Ming, W. C., Trindade, N. (2014). Development of colors with sustainability: a comparative study between dyeing of cotton with reactive and vat dyestuffs. Textile Research Journal, 84(10): 1009-1017. DOI: https://doi.org/10.1177/0040517513517962

Rosa, J. M., Tambourgi, E. B., Vanalle, R. M., Gamarra, F. M. C., Santana, J. C. C., Araújo, M. C. (2020). Application of continuous H2O2/UV advanced oxidative process as an option to reduce the consumption of inputs, costs and environmental impacts of textile effluents. Journal of Cleaner Production, 246: 1119012. DOI: https://doi.org/10.1016/j.jclepro.2019.119012

Santana, J.C.C., Dias, C.G., De Souza, R.R., Tambourgi, E.B. (2010). Applying of neural network on the wine sensorial analysis from barbados cherry. Journal of Food Process Engineering, 33 (Suppl. 1): 365-378. DOI: 10.1111/j.1745-4530.2009.00521.x

Schabbach, L. M., Marinoski, D. L., Güths, S., Bernardin, A. M., Fredel, M. C. (2018). Pigmented glazed ceramic roof tiles in Brazil: Thermal and optical properties related to solar reflectance index. Solar Energy, 159: 113-124. DOI:

https://doi.org/10.1016/j.solener.2017.10.076

Shen, J., Li, Y., He, J. H. (2016). On the Kubelka-Munk absorption coefficient. Dyes and Pigments, 127: 187-188. DOI: https://doi.org/10.1016/j.dyepig.2015.11.029

Torbati, S., Khataee, A.R., Movafeghi, A. (2014). Application of watercress (Nasturtium officinale R. Br.) for biotreatment of a textile dye: Investigation of some physiological responses and effects of operational parameters. Chemical Engineering Research and Design, 92(10): 1934-1941. DOI: https://doi.org/10.1016/j.cherd.2014.04.022

Tsao, Y. C., Vu, T. L., \& Liao, L. W. (2020). Hybrid heuristics for the cut ordering planning problem in apparel industry. Computers \& Industrial Engineering, 144: 106478. DOI: https://doi.org/10.1016/j.cie.2020.106478

Vedaraman, N., Sandhya, K. V., Charukesh, N. R. B., Venkatakrishnan, B., Haribabu, K., Sridharan, M. R., \& Nagarajan, R. J. C. E. (2017). Ultrasonic extraction of natural dye from Rubia cordifolia, optimisation using response surface methodology (RSM) \& comparison with artificial neural network (ANN) model and its dyeing properties on different substrates. Chemical Engineering and Processing: Process Intensification, 114: 46-54. DOI: https://doi.org/10.1016/j.cep.2017.01.008

\section{Figures}




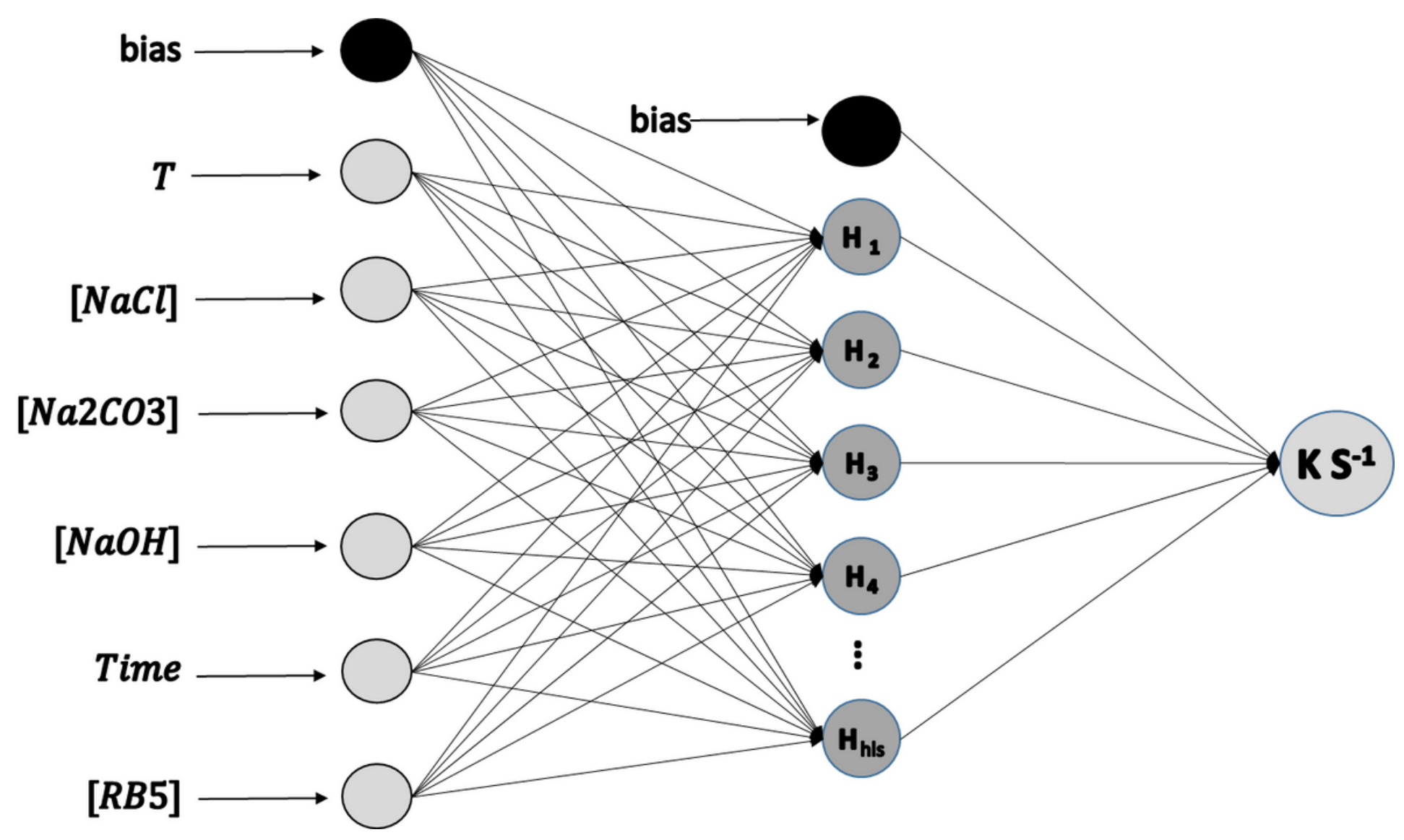

Figure 1

Base architecture of developed MLP\ANN

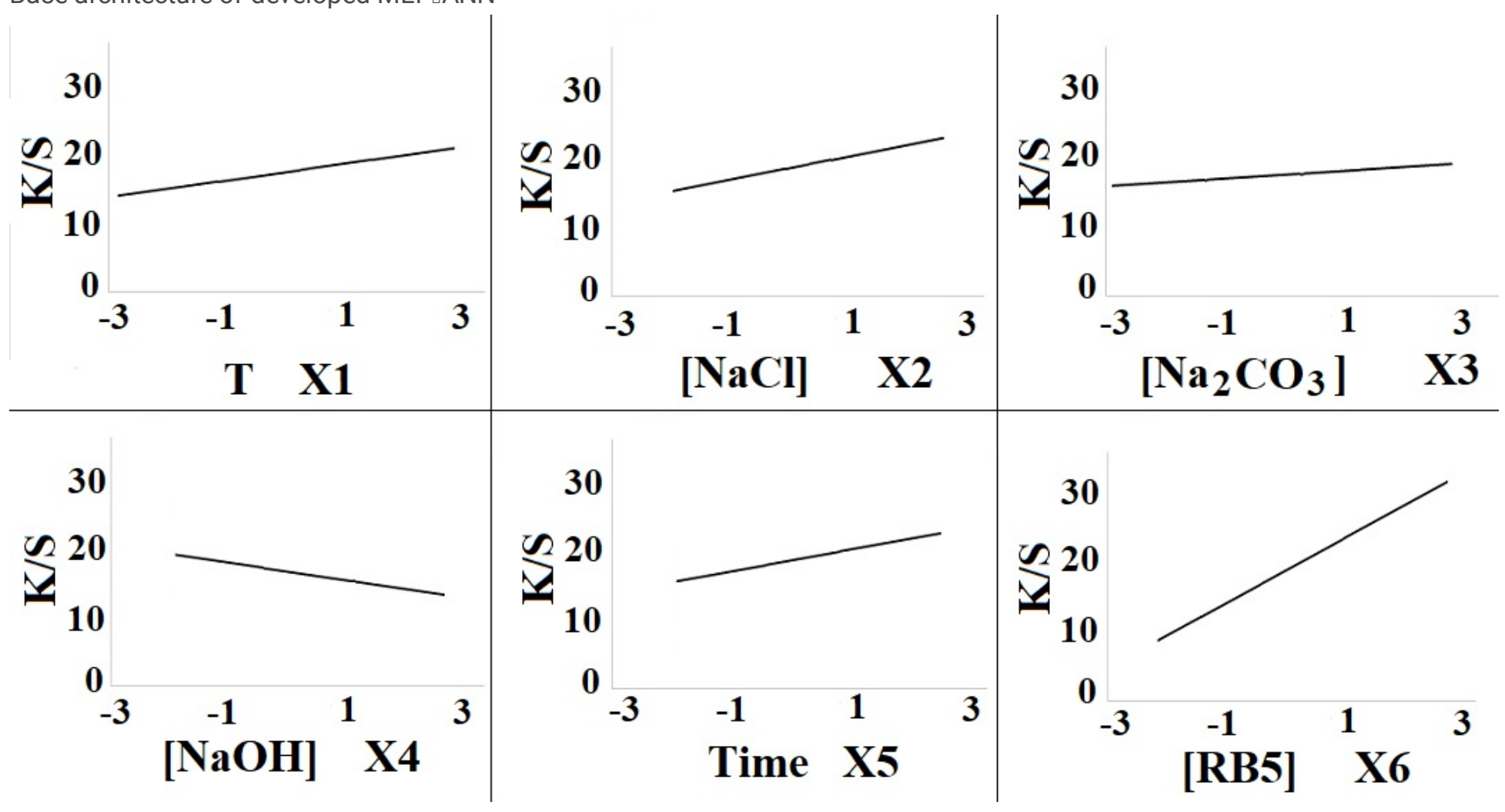

Figure 2 


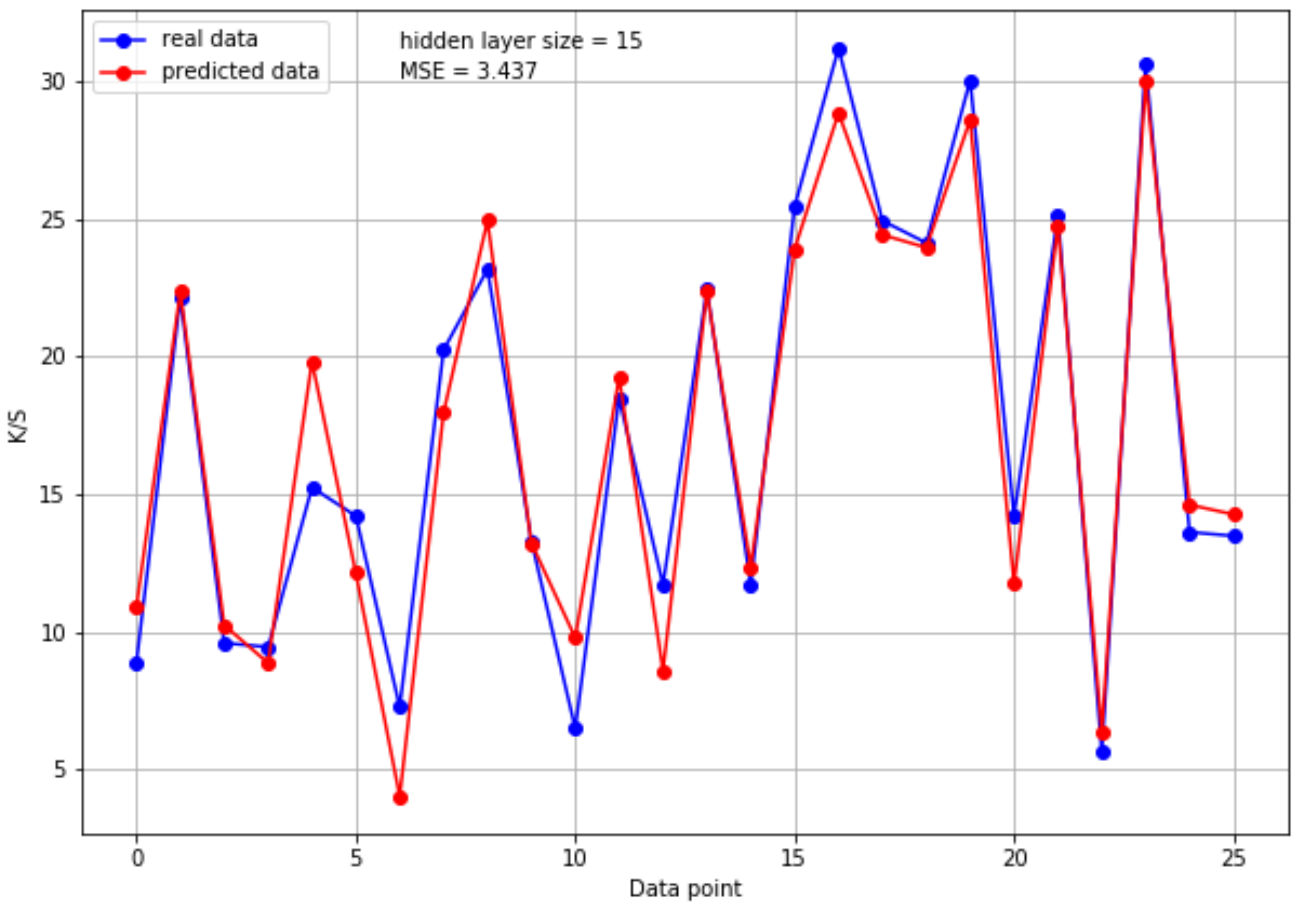

Figure 3

Best result obtained by $\operatorname{MLP} \square A N N(6,15,1)$

\section{Supplementary Files}

This is a list of supplementary files associated with this preprint. Click to download.

- GraphicalAbstract.png 